\title{
Intervention Strategies to Improve Students' Academic Performance in Public Secondary Schools in Arid and Semi-Arid Lands in Kenya
}

\author{
Jacob Merew Katamei ${ }^{1}$ \& Gedion A. Omwono ${ }^{2}$ \\ ${ }^{1}$ School of Education, Moi University, Eldoret, Kenya \\ ${ }^{2}$ School of Economics, Catholic University of Eastern Africa, Nairobi, Kenya \\ Correspondence: Jacob Merew Katamei. On P. O. Box 7702- 30100, Eldoret, Kenya.
}

Received: April 28, 2015

doi:10.11114/ijsss.v3i4.796

\author{
Accepted: May 12, $2015 \quad$ Available online: June 23, 2015 \\ URL: http://dx.doi.org/10.11114/ijsss.v3i4.796
}

\section{Introduction}

Fullan (2007) defined school as a community of active people where teachers in a classroom environment convey formal education to learners. A school therefore facilitates education. Schools, whether government aided or private sponsored, have stakeholders who undertake various activities. In light of this, students' academic performance has been a key issue in education with many believing that the education programmes are not well interpreted in schools; thus resulting in poor academic performance. This has resulted into finger pointing among stake holders. However, the fact of the matter is that something should be done to improve the current situation.

Kaggwa (2003) explained academic performance as the quality and quantity of knowledge, skills, techniques and positive attitudes, behaviors and philosophy that students achieve. The World Bank (2002) further observes that this achievement is evaluated by the mark or grade that student attain in tests or examinations done at the end of the topic, term or year or education cycle. Hence, the quality of the grades and the number of students that pass in various grades determine the level of academic performance. Academic performance is, therefore, a concern of people who have vested interest in schools. They may include parents, students, teachers, proprietors and the entire society that forms the school as a community. Unless all stakeholders are involved, school achievements including students' performance may not be realized (Dervitsiotis, 2004).

Every student has the potential to learn and become a responsible citizen if given a conducive environment. Therefore, it is worth mentioning that intervening at the earliest stages, can lead to students' success. Intervention can be defined as the systematic and explicit instruction provided to accelerate growth in an area of identified need (Kaggwa, 2003). Interventions can be provided by both special and general teachers and they are designed to improve performance relative to a specific, measurable goal. Interventions are generally based on valid information about current performance, whereby realistic implementation and ongoing student progress monitoring are essential. Therefore, for any intervention to be effective, the programmes designed should be based on clearly defined objectives, and the program should be monitored and evaluated (Kaggwa, 2003).

More particularly, students' needs should be analyzed and programs should be designed to address these. Of more importance is that intervention strategies should not be implemented because they are popular or interesting. Rather, they should be able to address the needs of the students in their institution, given that schools operate in different contexts; hence, no one size fits all. Approaches will vary according to the school context. Student support programmes, behavior modification, life skills programmes, parental involvement and capacity building are some intervention strategies to enhance students' performance (Kaggwa, 2003).

Mestry, Moloi and Mahomed (2007) stated that discipline in public schools ranks high as one of the major concerns expressed by all stake holders. There is a perception that student discipline is emerging as a serious problem that is making many schools ineffective institutions of learning and teaching. Mestry et al (2007) further point out that in some instances disciplinary policy is either ineffective, or not implemented and managed properly. Squelch (2001) contends that discipline is one of the key characteristics of an effective institution and is a necessary condition for effective teaching and learning. Mestry et al (2007) further revealed that students who display disruptive behavior are academically weak and often performs at their worst when they had to demonstrate learning output.

Life skills are important and required for successful living in the twenty first century (Rooth, 2000). Thus, Life Skills 
are essential for successful living and learning. Life skills include disciplined work habits, caring attitudes, and the ability to cope as well as to create one's own opportunities; all these factors are essential for success. Consequently students need an integrated Life Skills program in order to cope with their day to day academic issues. Life skills may include emotional skills, coping skills, health and hygiene skills, communication skills, and interpersonal skills. When Life Skills are mastered, the growth and development of student's becomes a reality and are then empowered.

School administrators should not underscore the role that involving families and parents can play in gaining the trust of students. Students whose parents are involved tend to fare better academically and socially than those whose parents are not involved (Mestry et al., 2007). To a large extent, the progress of students' educational development in the school context depends on effective contact with and cooperation between the parents and school personnel. Kurian (2008) asserts that active participation of parents in the education of their children is essential to improve discipline in schools as well as the academic performance of students. Hopkins (1998) observed that innovation in schools often fail because of the schools' inability or unwillingness to involve parents in a meaningful way in its program development and implementation.

Teachers are the largest single occupational group. Therefore, their roles have strategic importance for the intellectual, moral, and cultural preparation of people, (DoE, 2007). Teachers are the essential drivers of economic development and quality education. Therefore, for teachers to be able to perform better they must be equipped with skills and knowledge required. Smith (2001) observed that the roles of teachers cannot be overlooked if policy and educational change intends to have the desired effect. She adds that policy structures should be accompanied by a supportive process intended to strengthen the roles of teachers.

In America, the measure of school quality has been significantly achieved by school administrators in an attempt to improve their performance (Lareau, 2006). Lareau focused on curricula, class size, teacher proficiency, social-emotional environment, nutrition and availability of academic and health resources and technologies. The school administration has also been tasked by the state ministry of education to ensure that high-quality academic assessments, accountability systems, teacher preparation and training, curriculum, and instructional materials are aligned with challenging state academic standards so that students, teachers, parents, and administrators can measure progress against common expectations for student academic achievement; this has therefore ensured better academic performance in the academic institutions in the country.

South Africa educational reports indicate that majority of teachers has not been sufficiently equipped to meet the education needs of the growing nation in the 21 st century global environment. For instance, DeClercq (2008) states that a general consensus exists which holds that teachers need competencies such as subject matter, pedagogical and societal knowledge to enable them to understand their learners, learning and the environment. According to the Education White paper 6 (EWP6), inclusive education and training (IET) is about acknowledging that all children and youth can learn if they are provided with effective support (DoE,2001). Students at most schools have access to student support programs, but the question is whether these student support programs are addressing the real issues that concern their diversity.

In Uganda, the Education Act (1969) indicates that parent' responsibilities for example participation in the promotion of discipline, provision of learning materials, teachers' welfare, structural development and caring for children. Although the government white paper (1992) doesn't legalize parent participation in school management, it does not contradict it either but simply recommends parents' role play. According to Ssekamwa (2007), recognition has been given to crucial role play of parents and also on the rights and responsibilities of parents in the management of schools. This suggests that parental participation in school management is desirable and could lead to improved academic performance.

Considering recent studies in Kenya, factors contributing to poor academic performance include inadequate learning resources, inadequate monitoring by head teachers, understaffing, high teacher turnover rate, inadequate prior preparation, low motivation for teachers, large workload, absenteeism by both teachers and pupils, pupils lateness and lack of support from parents (Kurgat, 2008). Most of these cases have been attributed to poor intervention strategies by relevant authorities at the institutions of learning. This calls for the importance of the relevant stakeholders to come together to ensure that such intervention strategies are employed to improve the standards of education. An awareness of the right intervention strategies will have a great impact on the development of academic performance.

\subsection{The Genesis of the Phenomenon}

Secondary schools are central to the delivery of quality education needed to ensure success and participation in the country's growing economy. They should be designed to offer young people real opportunities to learn and acquire knowledge on various fields as they prepare to polish their skills in tertiary institutions. However, these aims cannot be achieved if students are experiencing difficulty in handling their academics and battling to cope with standard performance, thus reducing their overall academic performance. 
The main challenges facing the education sector today are issues of access, equity, quality, relevance and efficiency in the management of educational resources (Mutwol, Cheserek, Boit and Mining, 2013). In Arid and Semi-arid Lands (ASALs), socio-cultural and economic factors contribute to students' participation and dropout in public secondary schools. These factors include: poverty, low income level, inability of the parents to pay fees, cost sharing policies, provision of family labour and lack of basic needs. Other socio-cultural factors may include: early marriages, unplanned pregnancies and outdated traditional culture are some of the causes of low participation of secondary school students in education. It is imperative that socio-economic and cultural factors that hinder student participation in secondary education should be addressed to improve the overall participation in ASALs. This can be achieved through the employment of appropriate intervening strategies to improve students' academic outcomes.

However, existing evidence shows that although most secondary schools do have intervention strategies, some students still do not perform well; hence the possibility that strategies implemented in these schools are not achieving what they are supposed to. According to Marakwet Sub County Director of Education's (CDE) office report (2013), most of the existing interventions in public secondary schools in the county have achieved less in lowering failure rates, and availing students with additional opportunities to master key concepts that would hopefully raise their performance levels. Therefore, the paper identified intervention strategies that can be used to improve students' performance at public secondary schools in arid and semi arid areas, with a particular interest in Marakwet Sub-county.

\section{Justification of the Phenomenon}

Academic performance determines whether the students will proceed to institutions of higher learning either university or tertiary institutions. Hence, failure in national examinations spells doom for affected students whose lives may become uncertain and full of despair. A student's future education may therefore, be determined by his/her academic performance in the national examinations. Moreover, secondary school administrators in Kenya are under constant pressure to improve their students' grades in KCSE. On the other hand, public pressure on school administrators and teachers to improve academic performance has led to schools coming up with various performance improvement strategies including extra supplementary tuition, reward and punishment systems for well performing and poor performing students respectively. However, some of these strategies employed by schools to improve academic performance are not grounded on research evidence, while some like grade repetition and extra supplementary tuition have been shown to be counterproductive. Identifying the right intervention strategies, which is the basis of this paper, would thus go a long way in helping mitigate the current situation.

\subsection{The School as a Chaotic System and the Butterfly Effect}

Lampert (2005) described a form of educational uncertainty when she made it clear that not only do students add to uncertainty in the classroom, even the teacher. Thus, the teacher is an agent of chaos in the classroom. Every decision a teacher makes leads to an infinite number of possible new class scenarios. The teacher is the most chaotic element because he/she makes the decisions that drive many of the reactions of the other agents in the classroom. However, the failure to make a decision, in and of itself, is a decision and this contributes to chaos. According to Buchmann and Floden (2003), they observed the connection between teachings and learning as tenuous at best, which further creates uncertainty. Students' behavioral, emotional, and cognitive responses are affected by the contexts in which they live, of which school is only one. The student whose creative writing suddenly improves may have been inspired by a parent's comment, not the teacher's language arts unit. The student who has never completed her homework can turn in a carefully composed essay. The lesson that has always excited students can miscarry with the next year's class. Although experienced teachers have some sense of how students will react to a lesson or assignment, some uncertainty remains (Buchmann and Floden, 2003).

A question then arises on how the thinking about chaos theory helps teachers. It helps when any one of them looks at the way chaos theorists view uncertainty. Since they cannot account for everything, they should approach each task ready to deal with anything. Since a teacher cannot be certain as to results, they should do what they think based on their education and experience when designing something. This is a wise view and one held by many educators who do not actively think of chaos. Thus, actions must be taken in the classroom despite uncertainty caused by chaos (Buchmann and Floden, 2003).

The good news about chaos is that it is natural and a component of the universe (Cunningham, 2007). Chaos may cause uncertainty but it also creates the opportunities that create hope and change. Teachers need to prepare for chaos and accept uncertainty as a natural condition. In as much as teachers cannot control the entire universe, they can make impacts on the small slice of the universe they reside in despite all the chaos evident in it. The three principal conditions for a chaotic system are: that it operates in a non-linear way; that it is iterative (the output of one cycle becomes the input of the next); and that small variations in initial conditions lead to large differences in outcomes. Many systems within educational organizations appear to meet these conditions (Cunningham, 2007).According to Cunningham, the 
concepts of chaos theory can explain the way schools work. For instance, teachers do not exist as separate entities, but are affected by the relationships that exist within schools. It may also shed some light on how we can deal with and understand how things in our classrooms, schools, and entire communities are interrelated and all reflect in some manner upon each other.

The butterfly effect is one key aspect of chaos theory that holds much significance for educational settings. The butterfly effect means that a small and seemingly unrelated event in one part of a system can have enormous effects on the other parts of the system. The term 'butterfly effect' was made famous by a theoretical meteorologist, Edward Lorenz, who argued that a butterfly stirring its wings in Beijing today could unleash powerful storms in New York city next month. Thus, one implication of sensitive dependence on initial conditions is the impossibility of predicting not only next year's weather, but the long term future of any chaotic system (Glickman, 2009).

In terms of school improvement, the butterfly effect can be understood in the light that it is impossible to predict the long-term effects of school improvement strategy. Thus, planning in a chaotic system like a school should be medium range (one or two years) rather than long range (five to ten years). Formal planning in an unpredictable school system should, therefore, focus on process rather than product with the goal of putting in place a stream of wise strategies designed to achieve the mission of the institution. Conclusively, the butterfly effect ensures that no lesson will ever go completely as planned, or have the same effect on any two students. It indicates the need for teacher flexibility in teaching, as well as the need for individual attention to students, each of whom is experiencing a given lesson within his or her own personal context (Glickman, 2009).

\subsection{Parental Involvement}

Family involvement in academics and learning remains important in the adolescent years (Spera, 2006). School educators recognize that schools alone cannot prepare students for academic success without the support of families. They acknowledge that families play a critical role in helping youth succeed in high school and beyond. Unfortunately, parental involvement in education tends to decrease across middle and secondary school, due in part to adolescents' increasing desire for autonomy and in part to changes in school structure and organization. Yet family involvement in education remains a powerful predictor of various adolescent outcomes (Spera, 2006).

Zhan, (2006) support the importance of family involvement in the high school years; whereby, intervention evaluations increasingly demonstrate that family involvement can be strengthened with positive results for youth and their school success. Such results can be achieved when there is a match among youth's developmental needs, parents' attitudes and practices, and schools' expectations and support of family involvement. According to Hill et al. (2004), three family involvement processes for creating this match emerge from the evidence base: Parenting consists of the attitudes, values, and practices of parents in raising youth. These three family involvement processes are the same as those that are related to academic and social-emotional outcomes in the early childhood and elementary school years. Parenting, home-school relationships, and responsibility for learning outcomes need to become more respectful of students' drive for independence, expanding cognitive abilities, and widening social networks.

\subsubsection{Parenting}

This refers to the family involvement process that consists of parents' attitudes, values, and practices in raising their youth (Hill et al., 2004). The parenting styles used to engage youth, the quality of parent-youth relationships, and the ways parents monitor youth behavior collectively and uniquely influence youth achievements. Warm and responsive parenting in youth of school going age is related to school success and positive social and emotional outcomes. Students with supportive parents exhibit higher rates of self-reliance, identity formation, school performance, and positive career-planning aspirations, as well as lower rates of depression and delinquency. Students who share trusting relationships with their parents - characterized by mutual and sustained bonds and open communication — have higher grade point averages (GPAs) and better physical health and are more likely to disclose information to their parents that will keep them out of trouble(Zhan, 2006). Students benefit when these supportive and mature relationships with parents begin in the middle school years. In one study of low-income students, the degree to which mothers emotionally enabled and encouraged autonomous decision making in everyday conversations with their teenage children predicted whether they dropped out or completed high school and enrolled in college later (Spera, 2006).

Emotional responsiveness is one component of parenting style, which also includes how parents use discipline and control to interact with and raise their children. Different parenting styles are associated with different patterns of youth development. Other studies (Spera, 2006; Zhan, 2006) suggested that an authoritative style, which is responsive, warm, and firm but democratic, is associated with more positive educational outcomes than an authoritarian style, which is characterized by strictness and unilateral parental decision making. However, recent research shows that parenting styles and their impact differ among ethnic groups. These variations are due to a confluence of factors, including cultural traditions and norms and contextual variables. 
The nature of the parent-youth relationship is not only important for individual student outcomes such as academic achievement, but also for participation in out-of-school time activities that can benefit youth academically, socially, and emotionally(Zhan, 2006). For instance, when students feel more supported by their families and their families are more engaged in a variety of youth contexts, they are more likely to sign up for and stay involved in structured out-of-school time activities (e.g., after school programs, band, team sports, student government, etc.) that are linked to academic and social benefits. In contrast, students with disengaged or restrictive parents are less likely to participate in out-of-school time activities (Zhan, 2006). Disengaged parents are unlikely to be involved in their children's schools and unlikely to manage their children's time use, while restrictive parents set many rules but do not generally provide academic or other forms of support. Unfortunately, students of restrictive parents are less likely to have enriching home environments and would likely benefit from organized out-of-school time activities the most (Zhan, 2006).

On the other hand, monitoring represents a parent's attempts to know what is going on in their student child's life (Gonzalez-DeHass et al., 2005). Monitoring of social activities, such as being aware of their child's whereabouts, decreases school problems, substance use and delinquency, and promotes social competence and good grades. By monitoring adolescents' academic and social lives, parents can prevent emerging problems from becoming big ones, foster identity achievement, and promote academic growth. Parental monitoring is also linked with student's pro-social competency, fewer problem behaviors, and school adjustment and engagement; the latter refers to whether or not students pay attention in class, take school seriously, and want to do well in school. Parental monitoring is most effective for academic motivation and achievement when adolescents perceive their parents as truly invested in their well-being and caring about them (Gonzalez-DeHass et al., 2005). However, the effect of parental monitoring might differ for girls and boys. For at-risk inner-city boys, school engagement was greater when parental monitoring was high, but for girls, school engagement depended on both high parental monitoring and high family cohesion (Gonzalez-DeHass et al., 2005).

\subsubsection{Home-School Relationships}

This refers to the formal and informal connections between the family and school (Dounay, 2006). Home-school relationships seem to be important for youth as they are for younger children. Although home-school relationships tend to wane during or even before children reach adolescence, such relationships continue to play an important role in students' outcomes. Dounay, (2006) observed that aspects of home-school relationships include communicating with teachers and school personnel, attending school events, volunteering at school, and participating in Parent-Teacher Associations (PTA) and leadership groups.

The extent to which parents attend and volunteer at school functions, for instance, has a consistent positive impact on adolescent academic achievement (Dounay, 2006). There are several reasons why home-school relationships matter in secondary school for instance involvement and presence at school helps parents monitor their child's academic and social progress, acquire information they need to make decisions about their children's academic future, and foster positive relationships with school staff. Home-school relationships also increase student achievement by conveying to both teachers and parents beliefs about the importance of education and appropriate behaviors for adults in society. In addition, when families of diverse backgrounds are involved at the school level, teachers become more aware of cultural and community issues and, in turn, become more likely to engage and reach out to parents in meaningful and effective ways.

Home-school relationships are also linked to various student achievement outcomes beyond grades, including adjustment across transitions and students' educational expectations for themselves (Dounay, 2006). For example, parents' frequent contact with school personnel and involvement in school policies and parent-teacher associations are positively related to students completing high school. Students also make successful transitions from middle to high school when parents monitor their progress, evaluate that information, and intervene by actively communicating with teachers.

However, as in earlier periods of development, family involvement in adolescence may function differently and serve different purposes depending on parents' levels of education and ethnicity. In one longitudinal study, when parents with higher levels of education were involved, youth exhibited fewer behavior problems, which, in turn, was associated with achievement and aspirations. By contrast, when parents with lower levels of education were involved, family involvement was related to student aspirations for success but not achievement. Moreover, in the same study, family involvement was more strongly related to achievement (Hill et al., 2004).

\subsubsection{Responsibility for Learning Outcomes}

Among students, responsibility for learning is an aspect of parenting that places emphasis on homework management, educational expectations, and encouragement for college students (Spera, 2006). Under homework management, parents are less likely to be directly involved in the homework content of high school students as compared to lower schooling 
children. Nonetheless, parental encouragement and concrete help in managing homework supports students' learning, helping them to complete homework more accurately, so that when they study on their own, they can do so with fewer problem behaviors. Such help can also decrease conflict over homework and raise grades. However, the association between involvement and achievement can be bi-directional, such that student behavioral problems and poor achievement can also prompt high levels of involvement and time spent in helping with homework specifically because of the needs of the students (Spera, 2006).

High parental expectations also improve student outcomes (Zhan, 2006).For instance, parental expectations for students' success and high expectations for achievement stand out as the most significant influences on high school seniors' achievement growth, high school credits completed, and enrollment in extracurricular academic high school programs. When students perceive that their parents have high educational goals, they have more interest in school, greater academic self-regulation, and higher goal pursuits (Zhan, 2006).

One explanation for why responsibility for learning is so important in parents is that parents' aspirations and expectations affect student aspirations and expectations of themselves, and this, in turn, affects students' achievement (Zhan, 2006). When students perceive that their parents value education, they are more likely to feel competent and motivated in their studies. In fact, the academic encouragement parents provide is even more powerful than the support provided by friends and teachers. The extent to which parents convey and communicate these expectations is more important. The more the families discuss school issues, the more positive impact their expectations can have on their children's academic achievements. High parental expectations also play a mediating role between risk factors and student achievements (Zhan, 2006).

Parents' constant encouragement and discussions about school and higher education also promote students' college aspirations and preparation (Hill et al., 2004). Parent discussions with their youth about educational issues are associated with greater likelihood of enrolling in college. When parents encourage college enrollment and students perceive parents' interest in their school success, the students sign up for academic tracks in high school associated with college access (Hill et al., 2004). Summarily, this review demonstrates that the three family involvement processes of parenting, home-school relationships, and responsibility for learning outcomes are critical for secondary school students' academic achievement, social development, participation in settings other than school that promote healthy development, and opportunities for college enrollment.

\subsection{Capacity Building}

According to Aghenta (as cited by Chukwu, 2009), education is the greatest innovation man has created for his own continued improvement. It trains his brain, hand and heart and has placed him in the position of leadership on earth. Education gives man understanding and enlightenment; improve his intellect and skills as well as his attitude to his environment. Capacity building also known as skills development can be defined as development of the skills needed by excluded groups in order to participate fully in the labour market. It is further acknowledged that skills development is primarily considered to include professional or occupational skills.

The need for capacity building of the teacher is to equip him with the necessary skills to impact knowledge and have confidence in his profession to lace global competitiveness. Evidence from industrialized countries suggests that students of teachers with no professional preparation for teaching are less than students who have fully prepared teachers (Chukwu, 2009). Notwithstanding, what a country adopts as desirable instructional practice, be it direct/explicit instruction or child-centered, activity-oriented pedagogy, the availability of crops of competent teachers stand as a condition for successful implementation.

According to Dembele (as cited by Chukwu, 2009), educationists have come to realize that teachers are made and not born. Teacher education, both pre-service and in-service, is thus central to quality improvement in education (Dembele, 2005).Teachers are made through the educational preparation they undergo. On-the-job, they need professional development otherwise known as capacity building in order to get abreast with new teaching technologies. It has been noted that a significant number of teachers throughout the world are under-prepared for the profession (Villegas-Reimers, as cited by Chukwu, 2009). According Villegas- Reimers, the major setback in teaching as a profession is the problem of inadequate preparation of the teachers to be recognized as professionals. Therefore capacity building or professional development as it may be called should serve as an update.

Professional development should enable teachers to offer students the learning opportunities that will prepare them to meet world-class standards in given content areas and to successfully assume adult responsibilities for citizenship and work. It should also empower individual educators and communities of educators to make complex decisions; to identify and solve problems, to connect theory, practice, and student outcomes. Ogunde (as cited by Chukwu, 2009) stated that the major changes required to reform schools cannot be accomplished without professional development nor can it be achieved with outdated models of professional development. 
Capacity building of teachers should be a life-long process. Years back capacity building of teachers was in-service training consisting of short-term courses that would offer teachers new information on a particular aspect of their work. Only in the recent past the professional development of teachers has been considered a long-term process that includes regular opportunities and experiences planned systematically to promote growth and development in the profession (Villegas-Reimers, 2003). Professional development of teachers is very important, apart from the individual satisfaction or financial gain that teachers may obtain as a result of participating in professional-development opportunities, the process of professional development has a significant positive impact on education for sustainable development. This is because it enhances the teachers' beliefs and practices, students' learning, and the implementation of educational reforms both in and out of the classroom (Chukwu, 2009).

Levin and James (2001) states that programmes which promote capacity building should focus on the following: Developing survival skills, becoming competent in the basic skills of teaching, expanding one's instructional flexibility, acquiring instructional expertise, contributing to the professional growth of colleagues, and exercising leadership and participating in decision-making. The Republic of Kenya (2004) on Education Policy Framework, Sessional Paper No. 1 of 2005 stipulates and outlines policies and strategies to be undertaken and implemented by Government of Kenya in order to tackle challenges facing education and training. Applied in the strategic educational context of human resource management, Kenya's Sessional paper no.1 of 2005, chapter VI regards teachers and other staff as an important resource in the teaching learning process. Thus, their training and utilization therefore requires critical consideration. In line with this, the current government programmes for teacher education aim at providing qualified teachers and are therefore central to ensuring the provision of quality education.

For educational institutions to stay ahead in a rapidly changing environment, they must adapt to the new technologies and the changing world. These issues pose many problems and challenges for school managers. Consequently, the management of physical and human resources in the school system are of the utmost importance in order to achieve the overall goals and objectives of the schools. Thus, human resources management in education implies effectively coordinating the activities of staff, students and parents so as to achieve educational aims and objectives (Adeniyi, 2004).

For secondary schools to achieve high performance in the public examinations, they must recruit qualified teachers, they should secure modern buildings, provide adequate facilities and equipments to enhance teaching and learning while supervision of teaching should be carried out for quality control. Other bodies that could influence students' academic performance are administrators, managers, guidance counselors, Parents Teachers Association (PTA), curriculum specialist, funding agencies, non -teaching staff, inspectors and examination boards (Adeniyi, 2004).

With regards to educational policy, the supervision of instruction is the process of overseeing the work of teachers with the aim of assisting them to solve their instructional problems so that students can benefit maximally from classroom activities (Igwe, 2005). This can be effected with the involvement of the principal or any other official by interacting with teachers and students in the classroom regularly to monitor the teaching and learning process. According to Nwagwu (2004), the supervisor has the responsibility of monitoring and evaluating all staff activities and programmes of their organization. The major reason for this is to ensure dutiful compliance of all staff with established laws and declared goals through quality assurance, maintenance of standards and quality control.

\subsection{Students' Behavior Modification}

According to Mestry, Moloi and Mahomed (2007) discipline in public schools is ranked as one of the major concerns expressed by stake holders. There is a perception that student discipline is emerging as a serious problem that is making many schools ineffective institutions of learning and teaching. Mestry et al (2007) further point out that in some instances disciplinary policy is either ineffective, or not implemented and managed properly. Squelch (2001) observed that discipline is one of the key characteristics of an effective school and is a necessary condition for effective teaching and learning to take place. A study done by Mestry et al (2007) reveals that those students who display disruptive behavior are academically weak and often performs at their worst when they had to demonstrate learning output. In cases like these a zero tolerance approach to managing discipline is suggested.

Teaching a number of diverse students in one classroom has become an issue of concern for many educators. Teaching a group of students with emotional or behavior problems is even more challenging on the part of the teacher for nothing can be more frustrating in a classroom of 30 to 40 than have one or five students who exhibit negative or disruptive behavior. Educators have long understood that behavior or difficulties can keep pupils from functioning productively in class. Hence, for learning to take place, understanding how students understood their academic and social environment is very important. Learning about the students' performance or functioning in and outside the classroom is very necessary. Cochan-Smith (2004) pointed out that personal knowledge of students will result in an effective and responsive curriculum in the classroom. 
Observing students allows teachers to understand the students' changes by considering their backgrounds, behaviors, and interactions with others (Gartin, 2002). By observing and interviewing students, teachers can compile questions regarding the children's learning and development during academic or social situations. For example, a teacher may observe that a student does not interact well with peers in the classroom or the student is always out of seat when activity is given. A resulting question such as how can the teachers keep the student on task may become the source of trying new and different approaches with the student. Teachers, then, analyze classroom data to determine the success of their interventions. Teachers analyze instructional strategies for effective classroom management and behavior management compatible with the developmental characteristics of students with emotional problems.

Schools according to Cochan-Smith (2004) are expected to adjust classroom differences with disabilities by changing factors in the school environment that may not favor the student's progress. Gartin (2002) described it as differentiated instruction that is "using strategies that address student strengths, interests, skills, and readiness in flexible learning environment." In addition, Tomlinson (2000) emphasized that teachers must possess a solid understanding of a curriculum and its components to successfully differentiate instruction to meet diverse needs.

Mather et al. (2001) stressed that effective use of behavioral and cognitive strategies in the classroom may appear daunting even to experienced teachers. However, changing one's behavior and strategies is often the most efficient and effective means of improving all types of classroom behaviors, both disruptive and non-disruptive. As pointed out by Turnbull (2001) through practice, comes proficiency. The building block of emotions and behavior likely contains the largest and most diverse set of problems encountered in the classroom. By first understanding these problems and seeing the world through the eyes of the students and, by then developing and using a set of intervention strategies on a regular basis, problems of emotions and behavior can be effectively managed and changed in the classroom.

Managing students' disruptive classroom behavior can be a consuming task that reduces the amount of time teachers spend on instruction (Gartin, 2002). Effective classroom management can help to decrease disruptive classroom behaviors and increase student engagement in academic tasks. Furthermore poor classroom management has been linked to long-term negative academic, behavioral, and social outcomes for students (Gartin, 2002). One characteristic associated with effective classroom management is the amount of praise provided by teachers.

Teachers who deliver a high amount of praise typically experience lower off-task or disruptive behaviors from their students (Cochan-Smith, 2004). Praise has been shown to both increased appropriate behavior of disruptive students and increase academic engagement of students in general education (Gartin, 2002). Increasing academic engagement and decreasing disruptive behaviors allows more time for instruction.

The teacher's use of classroom accommodation/modification/adaptation such as modified instructional techniques to provide differentiated instruction and materials to meet students' individual need; assign peer buddies, peer tutors or cross-age tutors; provide alternative ways of completing assignments; adapt how the student can respond to instruction so that instead of answering questions in writing, allowing a verbal response; help limit unnecessary classroom disruptions and increase pupils' classroom participation (Levin and James 2001). Reinforcements and punishments have proved to be effective to modify students' misbehaviors. Modeling is a powerful tool to develop in students' good behavior. All of these reinforce the behavior management strategies in increasing academic performance through reduction of off-task behavior (Kaplan, 2005).

\subsection{Life Skills Education}

Life skills have been defined as "the abilities for adaptive and positive behavior that enable individuals to deal effectively with the demands and challenges of everyday life (Clarke, 2001). Life skills include psychosocial competencies and interpersonal skills that help people make informed decisions, solve problems, think critically and creatively, communicate effectively, build healthy relationships, empathize with others, and cope with managing their lives in a healthy and productive manner (Clarke, 2001). Essentially, there are two kinds of skills - those related to thinking termed as thinking skills and skills related to dealing with others termed as social skills. While thinking skills relate to reflection at a personal level, social skills include interpersonal skills and do not necessarily depend on logical thinking. It is the combination of these two types of skills that are needed for achieving assertive behavior and negotiating effectively (Rooth, 2000). Emotional skills can be perceived as a skill not only in making rational decisions but also in being able to make others agree to one's point of view. To do that, coming to terms first with oneself is important. Thus, self-management is an important skill including managing/coping with feelings, emotions, stress and resisting peer and family pressure. Young people as advocates need both thinking and social skills for consensus building and advocacy on issues of concern (Rooth, 2000).

Everywhere, education is seen as the main way of enabling individuals and nations alike to meet the ever increasing economic, technological, social and personal challenges. Education is expected to prepare young people for the world of work and for economic independence; to enable them to live constructively in responsible communities; and to enable 
them to live in a tolerant, culturally diverse and rapidly changing society. Perhaps above all, it is expected to help young people to build lives that have meaning and purpose in a scarcely predictable future (Rooth, 2000).

This has led to re-organizing of the education systems all over the world so that they provide not only high standards of academic qualifications, including literacy and In numeracy but also inculcate skills such as creativity, communication, empathy, adaptability, and social skills, all of which are being increasingly emphasized by employers and others in the global society. More so, in this age of information explosion education systems face the ever increasing challenge of providing skills to acquire and process information as it is neither possible to provide students with all the information available, nor is it possible to predict what knowledge would be required 20 years from now, hence the focus on skills (DoE, 2007).

It is envisaged that in the changed educational process the learning, while continuing around the traditional school subjects, namely, language(s), mathematics, science, social sciences, art and aesthetics, work experience, health and physical education, should move beyond mere acquisition of knowledge of concepts and facts of these subjects (Fullan, 2007). Though the textbooks may continue to remain the principal source of teaching-learning, the activities the methodology incorporated in the chapters should be skill oriented as opposed to provision of knowledge only.

According to Rooth, (2000), host of factors that promote high risk behavior (such as alcoholism, drug abuse and casual relationships) are boredom, rebellion, disorientation, peer pressure and curiosity. The psychological push factors such as the inability to tackle emotional pain, conflicts, frustrations and anxieties about the future are often the driving force for high risk behavior. Life skills training is, therefore, an efficacious tool for empowering the youth to act responsibly, take initiative and take control. It is based on the assumption that when young people are able to rise above emotional impasses arising from daily conflicts, entangled relationships and peer pressure, they are less likely to resort to anti-social or high risk behaviors (Rooth, 2000).

Creative thinking is a novel way of seeing or doing things which is a characteristic of four components- fluency (generating new ideas), flexibility (shifting perspective easily), originality (conceiving of something new), and elaboration (building on other ideas).Decision making helps students to deal constructively with decisions about their lives. This can have consequences for academic performance. It can teach students how to actively make decisions about their actions in relation to academics (Rooth, 2000).

Rooth (2000) points out that Life Skills are needed for successful living in the twenty first century. Life skills includes disciplined work habits, caring attitudes, and the ability to cope as well as to create one's own opportunities and all these factors are essential for adult success. Consequently students need an integrated Life Skills program in order to cope with their day to day academic life. Life Skills are essential for successful living and learning. Life skills may include emotional skills, coping skills, health and hygiene skills and communication.

\subsection{Student Support Programmes}

Secondary schools can provide a range of supports to boost students' academic performance. Student support within the education system is defined as all activities that increase the capacity of schools to respond to diversity and to challenges faced by their students, lecturers and staff as a whole (Kerr and Nelson, 2008). It would be difficult to improve academic performance without providing sufficient individual student support. Improving student support is inextricably tied to student engagement, and engagement for each student can only be accomplished through a more personalized academic and intellectual programme. Various researchers (Clarke, 2001; Delgado, 2001; Gartin, 2002; Burden, 2005) have referred to student support as including: mentoring, counseling, coaching, advice and guidance and tutoring. In addition, students can be given academic support through extra lessons, remedial lessons, reading labs these should be facilitated by a qualified and dedicated person who supports the school's vision.

Counselors, for instance, can be particularly influential with students from disadvantaged backgrounds (McDonough, 2004). In schools with limited resources and high counselor caseloads, mentoring programs or drop-in offices staffed by students or other community volunteers can be helpful (Schneider, 2006). Counseling should be supported by assessment data as part of a concerted "early warning system," beginning in form one, that identifies struggling students and ensures that they get the additional help they need (The Education Trust, 2005). Additional steps to help keep students engaged and learning include: A positive relationship with a caring adult mentor, which can be provided individually or in groups; by teachers, other school staff, fellow students, or members of the community; and either in the school or outside the school (Lerner and Brand, 2006). Another support program is advisories which include small supportive groups led by school staffs that develop a personal relationship with students (Herlihy and Quint, 2006). Small learning communities, in which students sharing the same cadre of core-subject teachers in a personalized environment feel that their teachers know and care about them (Herlihy and Quint, 2006).

Another support program is Mentoring where one or more teachers, tutors, coaches or mentors work on a regular, 
one-to-one or small group basis with students (The Education Trust, 2005). It is important to note that the student/mentor relationship may be a powerful influence in a student's life, particularly for those students who are vulnerable for a range of reasons outside the mentoring relationship. Mentoring programs and relationships need to be carefully managed for the safety of all involved. For this reason, the attention of staff considering taking on the role of mentor, and their supervisors, is specifically directed to the obligations set out in the school's Code of Conduct (Herlihy and Quint, 2006).

All programs providing students with extra support through mentoring need to be planned so they fit into the normal working patterns of a school. The time commitment and timeframe needs to be made clear and agreed upon by all parties, including the student, to avoid disappointment. In mentoring arrangements specific goals and a conclusion date need to be set. Mentors and students need to have a space to meet. This could be a section in the library, the assembly hall or another space within the school (Lerner and Brand, 2006).

The Education Trust (2005) established that low performing schools are characterized by lack of academic standards, high levels of disruptions and violence, high rates of students and staff absenteeism, high dropout rates, high rates of staff turnover, and an overall negative school atmosphere where parents are hardly involved in school programs and activities. In Kenya, (Kaggwa, 2003 and Adongo, 2006) established that low performing schools were characterized by inadequate school facilities, lack of active participation of students in the teaching-learning process, and poor overall school atmosphere in terms of organization, rules and student-to-student interaction calling for strategic intervention to close this gap.

\section{Strategic Interventions in Public Secondary Schools in Arid and Semi-Arid Lands (ASAL) in Kenya.}

\subsection{Parental Involvement Strategy}

On the influence of parental involvement strategy on students' academic performance in public secondary schools in ASAL areas in Kenya, schools as organizations involve parents in fee payments and in the supervision of student's academic progress. Most parents attend parent meetings and there is a parent's teachers association which every parent of a given school is a member. The work of teachers is to ensure that the students perform well academically. Parents mostly play a subsidiary role of providing financial support. As such, it is the teachers who are charged with the responsibility of disseminating knowledge to students to ensure better academic outcomes. Spera (2006) pointed out that parental involvement in education tends to decrease across middle and secondary school, due in part to adolescents' increasing desire for autonomy and in part to changes in school structure and organization.

\subsection{Provision of Support Programs Strategy}

In respect to the influence of student support programmes strategy on students' academic performance in public secondary schools in ASAL areas in Kenya, schools have assigned a mentor to lead and guide students, counseling programmes are available to students, remedial coaching is provided to slow learners and students are properly tutored. The strategies of providing academic and psychosocial support to the students have enabled the schools to realize good grades. Extra coaching for instance helps the weaker students to be at bar with other students thus enabling the school get good grades. Mentoring of students by teachers and adults is crucial for their success. The Education Trust (2005) noted that the presence of a caring adult in their life is important in assisting students to overcome adversity and achieve at school. Effective mentoring seeks to provide such a presence by establishing a trusting relationship between the student and mentor that: focuses on the needs of the student; models and fosters caring and supportive relationships increases self-confidence, awareness and management of behavior and positive attitudes towards a assisting others.

\subsection{Capacity Building Strategy}

In regard to the influence of capacity building strategy on students' academic performance in ASAL areas in Kenya, the teachers are continuously inducted in workshops and trainings for capacity building, teachers are involved in decision making to improve on their leadership skills, teachers are regularly taken through leadership courses and programs and teachers are often enrolled in fully sponsored in-service training programs by the employer. Good academic performance is realized due to, qualified teachers and adequate learning materials availability. As such, most teachers in public schools in ASAL areas in Kenya are already better trained to effectively impart relevant knowledge to their students. Thus, capacity building is just a subsidy to supplement their impressive competence in equal measure. Adeniyi (2004) found out that for secondary schools to achieve high performance in the public examinations, they must recruit qualified teachers, they should secure modern buildings, adequate facilities and equipments should be provided to enhance teaching and learning while supervision of teaching is carried out for quality control.

\subsection{Behaviour Modification Strategy}

On how behavior modification strategy impacts students' academic performance in ASAL areas in Kenya, students are sensitized on the importance of having good role models, punishment is administered to offenders according to their 
level of misdemeanor, exemplary behavior is usually acknowledged with positive reinforcements and students are trained on how to monitor and evaluate their behavior and set goals. Good behavior guarantees good grades. This is because students do not waste their study time on other unnecessary things. Desirable behavior is reinforced in schools by rewarding the most disciplined students. Gartin, (2002) pointed out that teachers who deliver a high amount of praise typically experience lower off-task or disruptive behaviors from their students. Praise has been shown to both increase appropriate behavior of disruptive students and increase academic engagement of students in general education.

\subsection{Provision of Life Skills Strategy}

On how Life Skill strategy affects students' academic performance in ASAL areas in Kenya, students in the school are good at solving problems, most students are able to think creatively, students are able to communicate effectively and students are able to cope in stressful situations. Imparting students with Life Skills knowledge enables them to be assertive. The students become judgmental thus will not involve themselves in disruptive activities. This will ensure that the students use the time available for studies. Rooth (2000) points out that Life Skills are needed for successful living in the twenty first century. Life skills include disciplined work habits, caring attitudes, and the ability to cope as well as to create one's own opportunities. Consequently students need an integrated Life Skills program in order to cope with their day to day academic life. Thus, Life Skills in ASAL areas in Kenya, has led to successful living and learning.

\subsection{Academic Indicators Strategy}

On academic performance indicators strategy in ASAL areas in Kenya, good grades in national examinations, syllabus completion on time, improved student discipline and excellent performance in inter-school academic contests shows that the school is performing well academically. A good grade in the national examination is an indicator to good performance. However, the ability to complete the syllabus on time could be a major booster in posting even more impressive grades in the national examinations. World Bank (2002) notes that student achievement is evaluated by the mark or grade that student attain in tests or examinations done at the end of the topic, term or year or education cycle. Hence, the quality of the grades and the number of students that pass in various grades determine the level of academic success.

\section{Conclusion}

Parental involvement strategy in academics and learning. When students perceive that their parents value education, they are more likely to feel competent and motivated in their studies. In fact, the academic encouragement parents provide is even more powerful than the support provided by friends and teachers. The extent to which parents convey and communicate these expectations is more important. The more the families discuss school issues, the more positive impact their expectations can have on their children's academic achievements.

This strategic intervention when adopted, students will feel more supported by their families and they will perform well academically since they will not want to let down their loved ones. Students whose parents supervise their school activities for instance homework will pass in their exams. Parents are the first socialization agents to the students meaning that they understand more than anyone else so they play a critical role in the academic performance of the students. Besides their traditional role of providing financial support, parents should monitor their children's academic progress, acquire information they need to make decisions about their children's academic future and foster positive relationships with school staff. As such, they should attend all parents meetings for more briefings on their children's academic progress and this will improve academic performance of their children and the schools.

Student support programmes strategy in schools. This strategy is important because support programmes boost students' academic performance. The schools should invest heavily on remedial classes in order to assist the weaker students. Students are supposed to be guided by the adults especially by mentors on life issues. They also need guidance and counseling so as to be able to do the right things. The schools should continue to provide more support to boost their students' academic performance. Remedial coaching should be intensified especially to slow learners to enable them compete favorably with other students. Mentoring and counseling services should also be increased to the students to enable them live responsibly and put more effort in their studies. By proving the above support programmes will help improve student academic performance.

Capacity building strategy for teachers. It is very vital as it equips teachers with the necessary skills to impact knowledge and confidence in their profession. Schools should make it a tradition to have in-service training for teachers whereby various experts on the education sector are called upon to impart teachers with information. Training for teachers should be done regularly in order to equip them with the necessary skills. The fact that many thing are changing globally necessitates constant training. Once teachers are equipped with up to date knowledge and skills, this will enhance their confidence to impart knowledge to their students. The results will be improved student academic performance in schools. 
Behavior modification strategy. It should be coveted in the education system because discipline has been associated with academic achievement. Reinforcements and punishments have proved to be effective strategy to modify students' misbehaviors. Modeling is a powerful tool to develop in students' good behavior. All of these reinforce the behavior management strategies increases academic performance through reduction of off-task behaviors. Having disciplined students is perhaps the most rewarding thing a school would ask for. For this reason schools have to adopt strategies to curb indiscipline such as, punishing offenders while at the same time rewarding those with desirable behavior. Besides these, there is need to sensitize students on the importance of having good role models. Schools should strive to instill discipline in their students as this will be a recipe for good academic performance.

Life skills strategy. Life skills includes disciplined work habits, caring attitudes, and the ability to cope as well as to create one's own opportunities and all these factors are essential for adult success. Consequently students need an integrated Life Skills program in order to cope with their day to day academic life. Life Skills are essential for successful living and learning. Life skills may include emotional skills, coping skills, health and hygiene skills and communication. It's beneficial as it makes students better members of the society. This enables them not only solve problems but also to think creatively. Having life skills knowledge enables students to relate well with others in a friendly manner. It also influences academic performance as they are able to become judgmental. Life Skills education when intensified in secondary schools enables students to be confident in solving day to day problems and fosters creativity thus improving academic performance.

\section{References}

Adeniyi, D, (2004). Psychosocial Environment and Human Resource Management in Educational Institutions, Journal of Educational Management and Planning, 1(14).

Birkland, T. (2001). An introduction to policy process. Theories, Concepts and Models of Public Policy Making. New York: ME Sharpe.

Buchmann, M., \& Floden, E. (2003).Detachment and Concern: Conversations in the Philosophy of Teaching and Teacher Education. New York: Teachers College Press.

Burden, P. (2005). Class room Management and discipline. New York: Longman Publishers.

Carnie, F. (2003).Alternative approaches to Education: A guide for Parents and teachers, New York: Tylor \& Francis Publications.

Chukwu, C. (2009).Capacity Building of Teachers-Challenges and Opportunities: Implication for Educational Sustainable Development. Paper Presented at the University of Ibadan International Conference on Education for Sustainable Development.

Cochan-Smith, D. (2004). Introduction to Special Education. Boston: Pearson Education, Inc.

Cotton, K., \& Wiklund, K. (2009).Parent involvement in Education http://www.nwlel.org/scpd/sirs/3/cub.ntml (retrieved on 24th march 2014).

Clarke, P. (2001). Learning Schools, Learning systems. London Continuum.

Cunningham, R. (2007). Chaos, Complexity and the Study of Education Communities. New York: Institute of Education.

De Clercq, F. (2008).Teacher Quality Appraisal and Development. Perspectives in Education, 26(1), 17-18.

Department of Education (2001). Education White Paper, 6. Bulding an Inclusive Education and Training Systems. Pretoria: Government Printers.

Department of Education. (2007). The National Policy Framework for Teacher Education and Development in South Africa. Pretoria: Government Printers.

Dervitsiotis, H. (2004). Productions/Operations Management, Durban: Irwin Publishing.

Dounay, J. (2006). Involving families in high school and college expectations. Denver, CO: Education Commission of the States.

Etal, N., \& Lorraine T. (2004).Parental School involvement and Children's Academic achievement. Pragmatics and Issues London: Blackwell Publishing Ltd.

Fullan, M. (2007).The new meaning of educational change. London: Teachers College Press.

Gartin, B. (2002).How to Use Differentiated Instruction with Pupils with Developmental Disabilities in the General Education Classroom. Arlington, VA: Council for Exceptional Children. 
Glickman, D. (2009). Supervision and Instructional Leadership. London: Allyn and Bacon.

Gonzalez-DeHass, A., Willems, P., Holbein, F. (2005).Examining the relationship between parental involvement and student motivation. Educational Psychology Review, 17(2), 96-123.

Herlihy, C., \& Quint, J. (2006). Emerging evidence on improving high school student achievement and graduation rates: The effects of four popular improvement programs. Washington, DC: American Institutes for Research.

Hill, N., Castellino, D., Lansford, J., \& Nowlin, P., et al. (2004). Parent academic involvement as related to school behavior, achievement, and aspirations: Demographic variations across adolescence. Child Development, 75(5), 1491-1509.

Hopkins, D. (1998). International Handbook of Educational Change. lamer Academic Publishers.

Igwe, S. (2005).Supervision, Evaluation and Quality Control in Education. In current Issues InEducational Management In Nigeria (Eds.) In N. A. Nwagwu., E. T. Ehiametalor, M.A Ogunu, Mon Nwadiani (Eds). Current issues in Educational Management in Nigeria, 32-45.

Kaggwa, V. (2003).Contribution of teachers' involvement in school administration on students' academic performance in private secondary schools. Kampala: Makerere.

Kurgat K. (2008). Management of Primary and Secondary Education in Kenya'.In E. O. Crucial Issues in the Management of Primary Education in Kenya. Nairobi: NAEAP Publication.

Kurian, V. (2008).Management strategies to improve the academic performance of previously disadvantaged secondary schools in the grade 12 examination. Pretoria: Government Printers.

Lampert, M. (2005).How Do Teacher Manage to Teach? Perspectives on Dilemmas in Practice. Harvard Educational Review, 55, 178-94.

Lareau, A. (2006). Assessing Parent Involvement in schooling in the USA. New York: Wiley.

Lerner, J., \& Brand, B. (2006). The college ladder: Linking secondary and postsecondary education for success for all students. Washington, DC: American Youth Policy Forum.

Levin, J., James F.(2001). Principles of Classroom Management: A Professional Decision Making Model. Boston: Allyn and Bacon.

Mather, N., Goldstein, S. (2001). Behavior Modification in the Classroom. Retrieved February 2, 2014, from http://www.matherandsmith.classroommanagement/text.htm.

McDonough, P. (2004). The school-to-college transition: Challenges and prospects. Washington, DC: American Council for Education.

Mestry, R., Moloi, K., \& Mahomed, A. (2007). Perspectives on zero-tolerance to discipline: towards maintaining a nurturing and secure school environment. Africa Education Review, 2, 96-97.

Mutwol, L., Cheserek, G.,Boit, J., \& Mining, P. (2013).Socio- Economic Factors Influencing Participation and Dropout of Students in Public Secondary Schools in Marakwet District, Kenya. Journal of Emerging Trends in Educational Research and Policy Studies (JETERAPS), 4(1), 185-19.

Nkata, J. (2006).The Changing Patterns of Parents Participation in primary school management in Mpigi District, Makerere University.

Owolabi, S. (2006)..Policy making and educational policy analysis. Kampala: Makerere University Press.

Republic of Kenya. (2012). Aligning Education and Training to the Constitution of Kenya (2010) and Kenya Vision 2030 and beyond: A Policy Framework for Education. Nairobi: Government Printer.

Rooth, E. (2000). Introduction to Life Skills. Via Afrika. Cape Town.

Schneider, B. (2006). Forming a college-going community in U.S. public high schools. East Lansing, MI: Michigan State University.

Spera, C. (2006). Adolescents' perceptions of parental goals, practices and styles in relation to their motivation and achievement. Journal of Early Adolescence, 26(4), 456-490.

Ssekamwa J. (2007). History and development of education in Uganda, Kampala: Fountain Publishers Ltd. The Education Trust. (2005). Gaining traction, gaining ground: How some high schools accelerate learning for struggling students. Washington, DC: Author.

Tomlinson, C. (2000). Reconcilable Differences: Standards-Based Teaching and Differentiation. Educational 
Leadership, 5(1), 6-11.

Turnbull, H., Wilcox, B., \& Stowe, M. (2001). IDEA: Requirements for Use of Positive Behavior Support: Guidelines for Responsible Agencies. Journal of Positive Behavior Support. 3(1), 11-18.

Zhan, M. (2006).Assets, parental expectations and involvement, and children's educational performance. Children and Youth Services Review, 28, 961-975.

\section{$(\mathrm{cc}) \mathrm{BY}$}

This work is licensed under a Creative Commons Attribution 3.0 License. 